\title{
Green Technological Innovation Efficiency and Financial Ecological Environment
}

\author{
Qian Ye*, Chunlin Cheng \\ Commercial College, Nanjing Normal University, Nanjing, China \\ Email: *yqian960311@163.com
}

How to cite this paper: Ye, Q. and Cheng, C.L. (2019) Green Technological Innovation Efficiency and Financial Ecological Environment. Open Journal of Social Sciences, 7, 132-151.

https://doi.org/10.4236/jss.2019.712011

Received: November 2, 2019

Accepted: December 6, 2019

Published: December 9, 2019

Copyright $\odot 2019$ by author(s) and Scientific Research Publishing Inc. This work is licensed under the Creative Commons Attribution International License (CC BY 4.0).

http://creativecommons.org/licenses/by/4.0/

(c) (i) Open Access

\begin{abstract}
The implementation of green technology innovation is a necessary choice for country to achieve "win-win" between environmental performance and economic performance. In this paper, environmental effects are included in the technology innovation system. Based on the panel data of 30 provinces and municipalities in China from 2006 to 2016, the efficiency of green technology innovation is calculated, and the influence of four sub dimensions of financial ecological environment, government governance, economic basis, financial development, system and integrity culture on green technology innovation is studied. The results show that: the efficiency of green technology innovation in each province in the sample data shows significant spatial autocorrelation, and the overall efficiency of green technology innovation is low. Besides, the financial ecological environment and its components can effectively promote the efficiency of green technology innovation. Furthermore, the control variables per capita GDP, foreign capital introduction and environmental regulation can significantly promote the green improvement of innovation efficiency. Thus, it is critical to furtherly improve the financial ecological environment, and give full play to the efficiency of financial effective service innovation and high-quality development of China's economy.
\end{abstract}

\section{Keywords}

Green Technological Innovation, Financial Ecological Environment, Environmental Effects, Unexpected Output

\section{Introduction}

In recent years, with the continuous improvement of China's total economic output, environmental pollution, resource shortage and ecological degradation have become the main obstacles to the sustainable development of China's 
economy. Many enterprises try to increase research and development investment to achieve the innovation-driven model and upgrading of the industrial structure, but they always overlook the pollution emission in production and the low efficiency of technological innovation; that is, ignoring the improvement of green technological innovation efficiency. In 2018, China's environmental performance index ranked 120 in the global 180 countries. And China ranked fourth from bottom in air quality. China must change the status of factor-driven economic development to achieve sustained prosperity. With the serious situation of deterioration of domestic ecosystem, worsening environmental pollution and tense resource constraints, China has proposed to develop green economy, promote green development and speed up the construction of ecological civilization at previous Party meetings. At the Fifth Plenary Session of the Sixteenth Central Committee of the Communist Party of China, it was proposed to build a resource-saving and environment-friendly "two-oriented society". At the Eighteenth National Congress, it was proposed to give prominence to the construction of "ecological civilization" and to incorporate it into the overall layout of "five in one" construction; and at the Fifth Plenary Session of the Eighteenth Central Committee, five development principles of "innovation, coordination, green, openness and sharing" were put forward as the train of thought, direction and focus of national development in the 13th Five-Year Plan and the longer term. The report of the 19th National Congress emphasizes once again that we should adhere to green development, promote people's prosperity, national prosperity and beauty, and make a fundamental, overall and historic strategic plan for the construction of ecological civilization. Adhering to green development is a profound revolution in the concept of development. We should take extraordinary measures in changing the mode of economic development, comprehensive treatment of environmental pollution, restoration of natural ecological protection, intensive utilization of resources, and improvement of the system of ecological civilization, so as to protect the ecological environment in an all-round, regional and whole process. In order to improve the level of technological innovation in the Chinese enterprises, people must pay attention to the innovation efficiency of enterprises as well as the R\&D investment of enterprises [1]. Especially, the China's innovation resources are relatively scarce now, so it is particularly important to improve the efficiency of green technology innovation of enterprises.

Nowadays, there is no authoritative or deterministic concept of enterprise green technology innovation. The earliest scholars defined it as "a general term for technologies, processes and products that reduce environmental pollution and save energy use" [2]. Later, some scholars took green product design and enterprise green management to the consideration of green technology innovation [3]. In China, there are different understandings of the green technology innovation and several representative viewpoints exist. Firstly, scholars summarize the concept and role of green technology innovation from the perspective of cost reduction [4]. Secondly, from the view of production process, some scho- 
lars take the green technological innovation as the whole process from green creativity to the final green achievements of production and manufacturing to the market [5]. Thirdly, they think that it is the organic unity of economic, social and ecological benefits, and take the sustainable development of technological innovation as green technological innovation [6]. In 2008, the China Committee for International Cooperation on Environment and Development (CCICED) made a report in which the concept of green technology innovation was extended to social and institutional innovation and the importance of public environmental technology innovation at the national level was also stressed. However, by any definition, green technological innovation of enterprises is not only a technological concept, but also a "green concept" emphasizing technological innovation. Through the R\&D and application of green products and green processes, the whole life cycle of products can be greened, and the economic and environmental benefits can be realized at the same time.

At present, the literatures about enterprise green technology innovation still focus on the role of factors such as input, technology transfer, industrial structure, financing system and government subsidies on the innovation ability of enterprises in various industries in China [7]. The internal motivation of enterprise technological innovation is attributed to the pursuit of profits. While the technological environment, customers' demands and government supervision are considered as external power sources [8]. With the gradual strengthening of environmental protection awareness, factors such as green barriers, environmental regulation and external environmental governance of enterprises have also been included in the research scope of factors affecting the efficiency of green technology innovation [9] [10] [11] [12]. At the same time, some scholars also studied the relationship between external financial environment and technological innovation of enterprises. They think that better level of financial development could bring higher level innovation investment of local enterprises [13]. It's also found that deepening the financial system can also promote innovation of regional enterprises and effectively alleviate the lack of innovation funds [14]. In addition, considering China's current economic development, the imbalance of economic and financial development among different regions [15] may affect the specific channels and effects of financial ecological environment to support green technology innovation.

To sum up, the existing researches in China mostly analyse the efficiency of green technology innovation from the micro-perspective of enterprises, measuring of the comprehensive macro-environmental indicators is still insufficient, and the characteristics of low added value, high pollution and high energy consumption in the Chinese enterprises are always ignored. The attention to green development is still insufficient. Therefore, the financial ecological environment index is introduced as an independent variable to study its impact on green technology innovation from four aspects: government governance, economic basis, financial development, system and honesty culture [16] [17] [18]. The researchers revealed the internal mechanism of its impact on green technology 
innovation and focused on the challenges of green ecological transformation. The green technology innovation index system was also established, which incorporated the environmental effects into the research framework.

The remaining part of this paper is arranged as follows: the second part discusses the mechanism of the impact of financial ecological environment on green technology innovation; the third part is the model construction, index measurement and numerical demonstration; the fourth part is the empirical results and analysis; the fifth part is the research conclusions and relevant policy recommendations of this paper.

\section{Mechanism Analysis and Research Hypothesis}

Since the 1990s, the overall level of the external financial environment of China's market has been greatly improved, and the level of regional financial ecological environment has also been significantly improved. Under this condition, the financial system can obtain innovative funds more efficiently. All these could be a driving force for promoting the development of green technology innovation. There is an inseparable relationship between the improvement of green technology innovation and the financial ecological environment of a region. Only by improving the financial ecological environment and solving the problem of coordination between economic growth and environmental protection, can we achieve green development. The specific mechanism is as follows:

In the first instance, a clean, efficient and transparent government governance is a necessary condition for the market to operate normally. A good government could ensure the full use of R\&D investment, including capital investment, human investment and energy investment, so as to achieve an efficient enterprise green technology innovation process [19]. However, an inefficient management of the local government could lead to a mismatch of resource and investment in enterprise innovation. And this will bring negative effects on the innovation investment and decision of the enterprise. The deficiencies in management system and policy implementation will lead to the increase of the cost and risk of green technology innovation [20], which will ultimately affect the benefits of technological innovation.

Secondly, the quality of regional economic operation is one core part of the regional financial ecological environment. The financial ecological environment with better economic foundation will provide more basic conditions for local enterprises' green technological innovation activities, and create more favorable resource advantages and information advantages. The economies of scale within a certain rang could be formed, which would improve the efficiency of enterprises' green technological innovation [21] [22]. However, in areas with poor economic foundations, enterprises lack of impetus for green technological innovation with an insufficient consumer demand and market demand.

In the next place, the financial risk management and capital allocation functions will significantly affect the benefits of green technology innovation [23]. 
Financial risk management services can help enterprises disperse risks, reduce innovation costs, and thus improve innovation revenue [24]. In addition, regions with high level of financial development will better improve the allocation of enterprise credit funds, and provide more external financing channels for local enterprises. Reasonable allocation of innovation resources could be achieved to promote the level of enterprise innovation efficiency [25]. On the contrary, regions with low level of financial development have higher degree of information asymmetry. Enterprise resource allocation efficiency and financing efficiency are also under lower conditions. Enterprise innovation investment cannot be effectively carried out with a relatively hightransaction cost [26].

In addition, the construction of market credit culture, legal environment and credit guarantee are indispensable infrastructure and system guarantee for the development of financial credit activities. A sound credit reporting system and a standardized accounting and auditing system can effectively preserve the credit records of enterprises, enhance the transparency of information between the two sides of the transaction, and reduce transaction costs. A perfect legal environment can effectively protect the property rights of enterprises, effectively curb malicious credit fraud and financial debt evasion. The protection of intellectual property rights can greatly improve the enthusiasm of enterprises for technological innovation. Therefore, the external credit system environment can play a positive role in enterprises' green technological innovation activities. A region with better external credit system environment can help to reduce enterprises' innovation risks [27], and attract more commercial credit and bank loans for enterprises' innovation activities [28], and could also have a great impact on enterprises' decision-making [29]. The honesty culture of an enterprise can also be regarded as the social cost based on trust. The high level trust in a region always company with a high social capital, which is conducive to improving the green technological innovation performance of enterprises in the region.

Based on the analysis above, we propose the following research hypotheses:

$\mathrm{H}_{1}$ : A region with better financial ecological environment has a relatively higher green technology innovation efficiency;

$\mathrm{H}_{2}$ : A region with better economic foundations has a relatively higher green technology innovation efficiency;

$\mathrm{H}_{3}$ : A region with higher government governance level has a relatively higher green technology innovation efficiency;

$\mathrm{H}_{4}$ : A region with higher level of financial development has a relatively higher green technology innovation efficiency;

$\mathrm{H}_{5}$ : A region with higher level of system and credit culture has a relatively higher green technology innovation efficiency.

To sum up, under the background that the driving force of China's economic development has changed from factor-driven, investment-driven to innovation-driven, the financial ecological environment can promote the green technological innovation activities of regional economic entities from four dimensions: economic basis, government governance, financial development and sys- 
tem and honesty and credit culture system.

\section{Model Setting and Variable Description}

\subsection{Model Setting}

Areas with similar technological innovation level tend to have spatial agglomeration effect. This paper tests the spatial autocorrelation by calculating the global Moran's I index and decides whether the spatial panel model should be selected for regression analysis. The calculation formulas are as follows:

$$
\begin{gathered}
\text { Moran'I }=\frac{\sum_{i=1}^{n} \sum_{j=1}^{n} W_{i j}\left(Y_{i}-\bar{Y}\right)\left(Y_{j}-\bar{Y}\right)}{S^{2} \sum_{i=1}^{n} \sum_{j=1}^{m} W_{i j}} \\
S^{2}=\frac{1}{n} \sum_{i=1}^{n}\left(Y_{i}-\bar{Y}\right), \bar{Y}=\frac{1}{n} \sum_{j=1}^{m} Y_{i}
\end{gathered}
$$

$Y$ denotes the green technology innovation efficiency of the first province, $n$ is $30, W_{i j}$ is the spatial weight matrix which is using $0-1$ weight matrix. When $i$ region is adjacent to $j$ region, $W_{i j}$ is 1 . When $i$ region is not adjacent to $j$ region, $W_{i j}$ is 0 .

Then, we use the knowledge production function [30] for reference to improve the model setting form, and test whether other development factors of provinces and cities have an impact on enterprise green technology innovation:

$$
Y_{i}=A K_{i} \alpha C_{i} \beta u_{i}
$$

$Y_{i}$ is the output of green technological innovation, $K_{i}$ is the input of R\&D capital, $C_{i}$ is the control variable that will influence green technological innovation, such as per capita GDP, foreign capital introduction, environmental regulation, etc. $u$ is a random perturbation term.

In order to reveal the relationship between financial ecological environment and green technological innovation more scientifically and comprehensively, based on this function, green technological innovation is set as dependent variable, financial ecological environment as core independent variable, and other related exogenous variables are included in the spatial panel model:

$$
\begin{gathered}
\mathrm{GRE}_{i t}=\alpha_{0}+\alpha_{1} \mathrm{FE}_{i t}+\sum_{k=1}^{n} \beta_{k} X_{i t}+\mu_{i}+\eta_{t}+\varepsilon_{i t} \\
\varepsilon_{i t}=\lambda W_{i j} \varepsilon_{i t}+v_{i t}
\end{gathered}
$$

The above model is a spatial error model, and the spatial effect between individuals is reflected in the perturbation term of the model. $\mathrm{GRE}_{i t}$ in the model is green technology innovation efficiency, $\mathrm{FE}_{i t}$ is financial ecological environment. $W_{i j}$ is a spatial weight matrix, $X_{i t}$ is a control variable, including PGDP, FDI and REG; $\mu_{i}$ is an individual effect of different provinces and cities; $n_{t}$ is a time effect of year, and $\varepsilon_{i t}$ is a random error term. In order to ensure the unbiasedness of measurement results, the range of neighbors in the selected spatial matrix is exogenous, there is no endogenous error. The quasi-maximum likelihood estima- 
tion (QMLE) method after orthogonal transformation is used to estimate the model. The orthogonal transformation method used in QMLE model overcomes the autocorrelation of error terms in the model, and thus obtains unbiased estimation results.

\subsection{Variable Description}

The data used in the model are the annual observations of 30 provincial administrative regions in China from 2006 to 2016. Due to the serious lack of data in Hong Kong, Macao, Taiwan and Tibet Autonomous Region, it is not studied for the time being. The main variables are selected according to the following criteria:

1) Green Technology Innovation (GRE). Green technological innovation refers to technological innovation in the process of enterprise innovation aiming at minimizing the production cost of products, combining with the principle of environmental integration. The fundamental focus of economic and innovation transformation is technological innovation and green ecological transformation, improve production efficiency and profit rate under green technology innovation to reduce ecological environment pollution [31] [32].

This paper constructs an evaluation system of green technology innovation from two dimensions of input and output, introduce industrial "three wastes", smoke and dust as the unexpected output, Select six indicators: capital input, energy input, manpower input, number of patent applications, output value of new products and unexpected output, use the DEA model with constant returns to scale and variable returns to scale to measure the efficiency of green technology innovation in provinces and municipalities and to test its spatial correlation. The index system is shown in Table 1 .

a) Capital input. $R \& D$ investment is the precondition for enterprises to carry out $\mathrm{R} \& \mathrm{D}$ innovation activities, create knowledge and realize green technology innovation. The $R \& D$ investment intensity of enterprises in various provinces is used to measure the investment in green technology innovation.

b) Energy input. Energy consumption is the basis of green technology innovation. It is included in efficiency measurement and measured by the annual total energy consumption (10,000 tons of standard coal) of each province.

c) Manpower input. R\&D personnel refer to those who directly engage in

Table 1. Index system of green technological innovation.

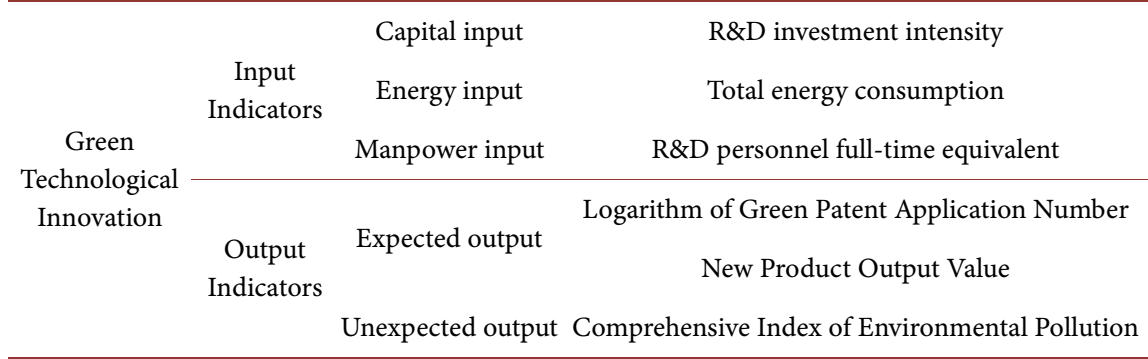


R\&D activities, as well as managers, administrators and clerks who directly provide services for R\&D activities.

d) Expected output. Green patents refer to invention, utility model and design patents with green technology as the theme of invention, reflecting industrial green technology innovation willingness. In view of the characteristics of industry patent intensive, the number of patent applications is less affected and restricted by the review ability of government patent review agencies, which can better reflect the true level of $R \& D$ innovation. At the same time, in terms of the economic output of green technology innovation, the indirect output index is the output value of new products in high patent intensive industries, which more comprehensively reflects the achievements of technological innovation. In order to avoid the interference of heteroscedasticity, some variables were processed by logarithm and the factory price index of industrial products was reduced based on 2006.

e) Unexpected output. As a "by-product" of expected output, the direct or indirect impairment of performance output (pollution emissions, etc.) in the process of technological innovation. Include the environmental effects in the research framework and select the discharge of industrial wastewater, $\mathrm{SO} 2$ and industrial solid wastes as the main sources of pollution in the manufacturing industry during the industrialization process; we fit five indicators to the comprehensive environmental pollution index of provinces and municipalities by using the method of entropy value.

Firstly, due to the incomparability of different dimensions among various pollution indicators, standardized treatment is carried out:

$$
P_{i j}=\frac{Q_{i j}}{\sum_{i=1}^{m} Q_{i j}},(i=1,2, \cdots, j=1,2, \cdots, m)
$$

$N$ is the number of provinces, $\mathrm{m}$ is the number of indicators, $Q_{i j}$ is the value of the $f^{\text {th }}$ pollution index of province $i$.

Secondly, calculate the entropy value of index $j$.

$$
e_{j}=-k \sum_{i=1}^{n} p_{i j} \ln \left(p_{i j}\right), k>0, k=1 / \ln (n), e_{j} \geq 0
$$

Find the difference coefficient of Index $j$. For the pollution index of item $j$, the bigger the difference of the index value, the bigger the left and right of the evaluation of the scheme, and the smaller the entropy value. Define the coefficient of difference:

$$
g_{j}=\frac{1-e_{j}}{m-E_{e}}, E_{e}=\sum_{j=1}^{m} e_{j}, 0 \leq g_{i} \leq 1, \sum_{j=1}^{m} g_{j}=1
$$

Then, calculate the weight of pollution index $j$ :

$$
w_{j}=\frac{g_{j}}{\sum_{j=1}^{m} g_{j}}(1 \leq j \leq m)
$$


Finally, calculate the comprehensive index of environmental pollution of each province. The specific results are shown as Table 2:

$$
s_{i}=\sum_{j=1}^{m} w_{j} \cdot p_{i j}(i=1,2, \ldots, n)
$$

2) Financial Ecological Environment (FE). The financial eco-environment score introduced by the Financial Research Institute of the Chinese Academy of

Table 2. Comprehensive environmental pollution index of provinces in 2006-2016.

\begin{tabular}{|c|c|c|c|c|c|c|c|c|c|c|c|c|}
\hline & 2006 & 2007 & 2008 & 2009 & 2010 & 2011 & 2012 & 2013 & 2014 & 2015 & 2016 & $\begin{array}{l}\text { Aver- } \\
\text { age }\end{array}$ \\
\hline Beijing & 0.009 & 0.009 & 0.008 & 0.006 & 0.006 & 0.006 & 0.005 & 0.004 & 0.004 & 0.004 & 0.004 & 0.006 \\
\hline Tianjin & 12 & 0.012 & 0.011 & 0.010 & 0.010 & 0.010 & 0.009 & 0.009 & 0.009 & 0.009 & 0.009 & 0.010 \\
\hline Hebei & 87 & 0.086 & 0.088 & 0.079 & 0.086 & 0.091 & 0.097 & 0.095 & 0.097 & 0.091 & 0.086 & 0.089 \\
\hline Shanxi & 048 & 0.047 & 0.042 & 0.049 & 0.045 & 0.052 & 0.051 & 0.053 & 0.057 & 0.053 & 0.054 & 0.050 \\
\hline Inner Mongolia & 0.034 & 0.039 & 0.035 & 0.036 & 0.040 & 0.044 & 0.042 & 0.041 & 0.040 & 0.045 & 0.048 & 0.040 \\
\hline Liaoning & 0.064 & 0.066 & 0.049 & 0.068 & 0.056 & 0.049 & 0.057 & 0.056 & 0.054 & 0.059 & 0.063 & 0.058 \\
\hline Jilin & 0.018 & 0.017 & 0.016 & 0.016 & 0.017 & 0.017 & 0.017 & 0.017 & 0.017 & 0.017 & 0.017 & 0.017 \\
\hline Heilongjia & 0.021 & 0.021 & 0.020 & 0.019 & 0.021 & 0.019 & 0.018 & 0.021 & 0.019 & 0.019 & 0.019 & 0.020 \\
\hline Shanghai & 0.022 & 0.021 & 0.021 & 0.018 & 0.017 & 0.017 & 0.016 & 0.017 & 0.016 & 0.016 & 0.016 & 0.018 \\
\hline Jiangsu & 0.083 & 0.084 & 0.082 & 0.074 & 0.074 & 0.074 & 0.074 & 0.075 & 0.073 & 0.076 & 0.075 & 0.077 \\
\hline Zhejiang & 0.051 & 0.053 & 0.055 & 0.053 & 0.053 & 0.054 & 0.047 & 0.047 & 0.045 & 0.045 & 0.045 & 0.050 \\
\hline A & 0.028 & 0.030 & 0.036 & 0.035 & 0.036 & 0.034 & 0.036 & 0.037 & 0.037 & 0.037 & 0.040 & 0.035 \\
\hline Fujian & & 0.036 & 0.039 & 0.039 & 0.041 & 0.038 & 0.042 & 0.033 & 0.035 & 0.032 & 0.030 & 0.036 \\
\hline $\mathrm{Ji}$ & 0.030 & 0.030 & 0.024 & 0.030 & 0.031 & 0.030 & 0.030 & 0.030 & 0.031 & 0.029 & 0.033 & 0.030 \\
\hline Shando & 0.070 & 0.069 & 0.083 & 0.074 & 0.076 & 0.080 & 0.073 & 0.071 & 0.072 & 0.075 & 0.080 & 0.075 \\
\hline & & 0.052 & 0.053 & 0.052 & 0.055 & 0.052 & 0.056 & 0.055 & 0.057 & & & 0.054 \\
\hline dbei & 34 & 0.034 & 0.033 & 0.032 & 0.032 & 0.032 & 0.035 & 0.033 & 0.032 & 0.033 & 0.033 & 0.033 \\
\hline מנan & 34 & 0.029 & 0.033 & 0.029 & 0.031 & 0.032 & 0.032 & 0.033 & 0.032 & 0.029 & 0.029 & 0.031 \\
\hline Guan & 0.059 & 0.057 & 0.062 & 0.058 & 0.054 & 0.052 & 0.050 & 0.052 & 0.050 & 0.053 & 0.050 & 0.054 \\
\hline & & 0.037 & 0.048 & 0.052 & 0.045 & 0.044 & 0.037 & 0.040 & 0.033 & 0.030 & 0.026 & 0.039 \\
\hline & 02 & 0.002 & 0.002 & 0.002 & 0.002 & 0.002 & 0.002 & 0.003 & 0.004 & 0.003 & 0.003 & 0.003 \\
\hline Chor & 0.022 & 0.024 & 0.021 & 0.020 & 0.023 & 0.017 & 0.013 & 0.012 & 0.013 & 0.014 & 0.014 & 0.018 \\
\hline Sichuan & 0.044 & 0.044 & 0.050 & 0.043 & 0.040 & 0.041 & 0.036 & 0.035 & 0.034 & 0.035 & 0.033 & 0.040 \\
\hline Guizhou & 0.018 & 0.021 & 0.016 & 0.016 & 0.019 & 0.019 & 0.016 & 0.018 & 0.023 & 0.023 & 0.020 & 0.019 \\
\hline Yunnan & 0.022 & 0.024 & 0.020 & 0.024 & 0.025 & 0.023 & 0.032 & 0.030 & 0.030 & 0.028 & 0.029 & 0.026 \\
\hline Shaanxi & 0.023 & 0.021 & 0.019 & 0.025 & 0.024 & 0.024 & 0.021 & 0.020 & 0.021 & 0.022 & 0.024 & 0.022 \\
\hline 1 & 0.013 & 0.012 & 0.010 & 0.012 & 0.012 & 0.011 & 0.015 & 0.016 & 0.015 & 0.015 & 0.015 & 0.013 \\
\hline Qinghai & 0.004 & 0.005 & 0.004 & 0.006 & 0.006 & 0.006 & 0.015 & 0.016 & 0.016 & 0.016 & 0.019 & 0.010 \\
\hline Ningxia & 0.008 & 0.008 & 0.008 & 0.008 & 0.009 & 0.016 & 0.011 & 0.010 & 0.010 & 0.011 & 0.010 & 0.010 \\
\hline Xinjiang & 0.011 & 0.011 & 0.011 & 0.012 & 0.014 & 0.015 & 0.015 & 0.020 & 0.024 & 0.023 & 0.021 & 0.016 \\
\hline
\end{tabular}


Social Sciences, it is a systematic exposition and characterization of the concept of financial ecology, which includes four aspects: regional government governance (GOV), economic basis (EOC), financial development (FD), credit system and integrity culture (SYS).

From the above theoretical assumptions, we can see that the improvement of financial ecological environment can promote the innovation activities of regional micro-economic entities from the input and output mechanism. The data of financial eco-environment is taken from China Financial Eco-environment Report. For the year when the data of financial eco-environment are missing, the data of last year should be used instead, because the index of financial eco-environment in different regions will not change much in the short term [33].

3) Per capita gross domestic product (PGDP). Regional GDP represents the total level of regional total purchasing power and effective market demand. Per capita GDP can measure the living standard of residents and the scale of effective market demand in a region. It is also an important indicator of the stage of economic development. Therefore, the per capita GDP is chosen to measure the market demand for innovative new products.

4) Foreign capital introduction (FDI). Foreign capital improves the green environmental performance of enterprises by enhancing the technology level of industries through technology spillover effect, but at the same time, there are also environmental resources problems caused by industrial transfer. This paper uses the proportion of the total industrial output value invested by foreign businessmen and Hong Kong, Macao and Taiwan businessmen in the industry to the total industrial output value of the industry.

5) Environmental Regulation (REG). Environmental regulation is a kind of institutional restraint put forward by the government to the environmental behavior of enterprises. Green technology innovation has the characteristics of high investment, high risk and significant externalities. At the same time, enterprises lack the motivation to implement it actively. Therefore, the government needs to solve this problem through institutional constraints. This paper chooses investment funds for pollution control to control the intensity of environmental regulation.

Data in this paper are collected from China Statistical Yearbook, China Scientific and Technological Statistical Yearbook, China Industrial Economic Statistical Yearbook, China Statistical Yearbook of Scientific and Technological Activities of Industrial Enterprises, China Environmental Statistical Yearbook, China Energy Statistical Yearbook, the official website of the State Administration of Intellectual Property and EPS Global Statistical Data Platform. Because the statistical caliber of the existing statistical data has changed many times, in order to avoid obvious deviation and maintain the consistency of statistical caliber, considering the continuity and integrity of the data, this paper finally screened out the relevant data of 30 provinces, municipalities and autonomous regions in the country from 2006 to 2016. Descriptive statistical analysis of variables is shown in Table 3. 
Table 3. Descriptive statistics of major variables.

\begin{tabular}{cccccc}
\hline Variable & Obs & Mean & Std & Min & Max \\
\hline GRE (crste) & 330 & 0.9129 & 0.0825 & 0.6290 & 1.0000 \\
GRE (vrste) & 330 & 0.9223 & 0.0809 & 0.6340 & 1.0000 \\
FE & 330 & 0.4445 & 0.1355 & 0.1160 & 0.9220 \\
GOV & 330 & 0.5140 & 0.1436 & 0.0000 & 0.9070 \\
EOC & 330 & 0.3544 & 0.1803 & 0.0200 & 0.9230 \\
FD & 330 & 0.4686 & 0.1389 & 0.1720 & 0.9340 \\
SYS & 330 & 0.4570 & 0.1551 & 0.0000 & 0.9650 \\
PGDP & 330 & 10.3946 & 0.5927 & 8.6634 & 11.6801 \\
FDI & 330 & 0.0237 & 0.0184 & 0.0004 & 0.0819 \\
REG & 330 & 1.3786 & 0.6857 & 0.3000 & 4.2400 \\
\hline
\end{tabular}

\section{Empirical Results and Analysis}

\subsection{Spatial Correlation Test}

This paper uses stata12.0 to test the spatial correlation of green technological innovation efficiency of every province and city in China, and calculates the global Moran index value of green technological innovation of enterprises. The calculation results are shown in Figure 1. In 2006-2016, the Moran values reflected by the curve were all greater than 0.2 , and the Moran values showed an overall upward trend except for a slight decline in 2009 and 2011. In the case of $5 \%$ significance level, $\mathrm{Z}$ value of Zhengtai statistic is more than $2.5, \mathrm{P}$ value is less than 0.05 , Moran value has passed the test of significance level, and can be tested by spatial econometric model.

Moran scatter plot divides enterprise innovation into four quadrants. Among them, the first quadrant represents the spatial connection form that High-Innovative provinces are surrounded by other High-Innovative regions, the second quadrant represents the spatial connection form that low-innovative provinces are surrounded by High-Innovative regions, and the third quadrant represents that low-innovative regions are surrounded by low-innovative regions, the fourth quadrant represents the spatial form in which the high-observed areas are surrounded by low-valued areas Due to space constraints, this paper reports scatter plots for 2010 and 2014 (Figure 2 and Figure 3), and summarizes the corresponding results of scatter plots into Table 4. From Table 4, we can see that enterprise innovation in Jiangsu, Zhejiang, Shanghai, Beijing, Tianjin and Hebei show obvious spatial agglomeration effect. The Southern Comprehensive Economic Zone with Guangdong as its core is gradually forming agglomeration, while the central and western regions are divided into regions with low innovation activities.

\subsection{Empirical Model Analysis}

According to the results of spatial correlation test and Hausman test, the SEM 


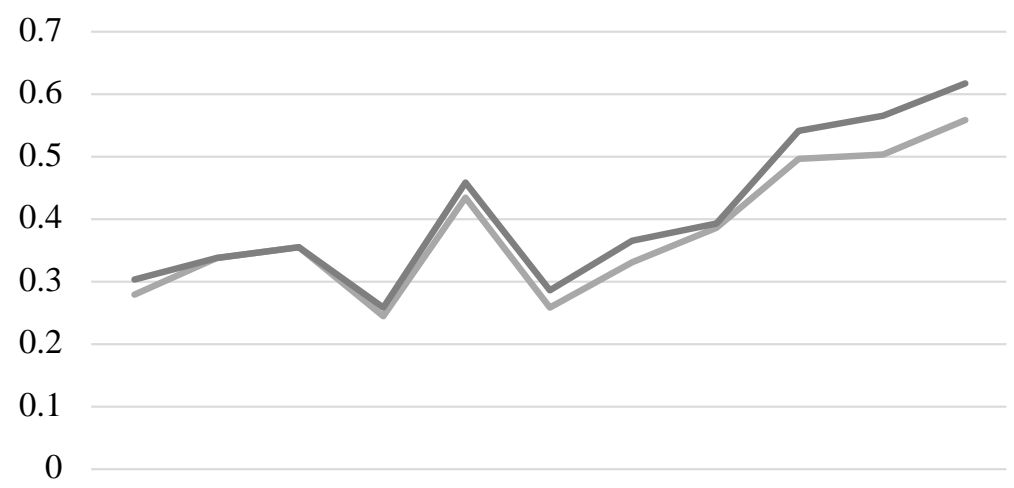

20062007200820092010201120122013201420152016

moran1 moran2

Figure 1. Moran exponential scatter plot.

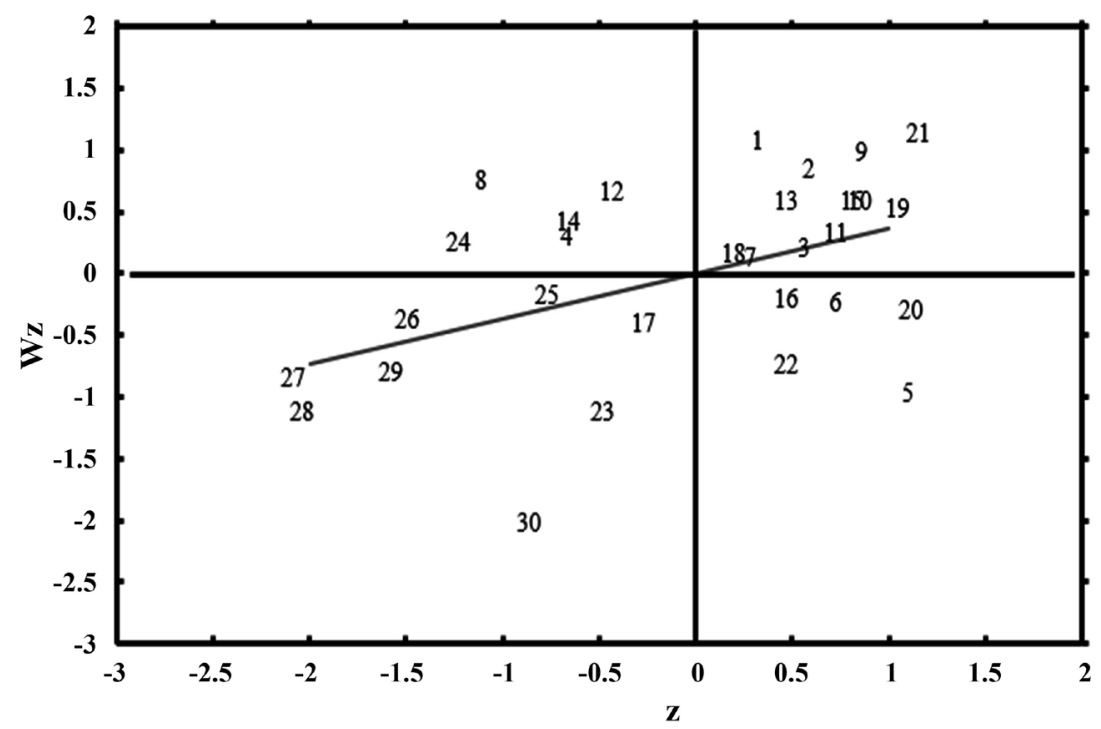

Figure 2. Moran index scatter plot (2010).

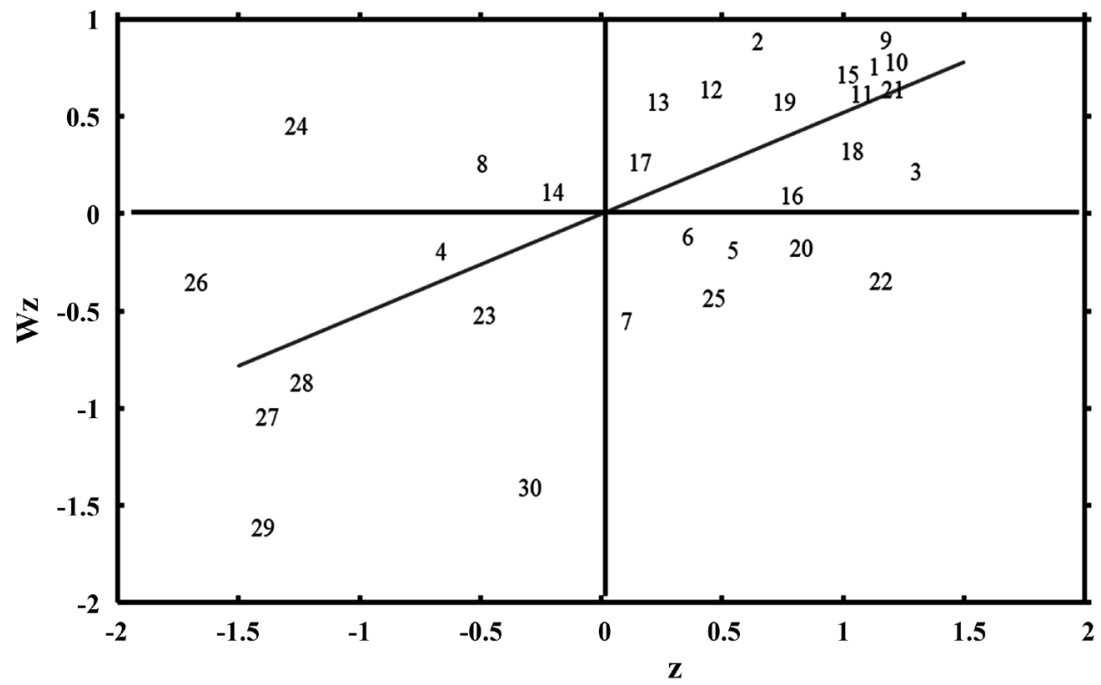

Figure 3. Moran index scatter plot (2014). 
Table 4. Provinces corresponding to the global scatter map for the representative years in 2006-2016.

\begin{tabular}{|c|c|c|c|c|}
\hline & $\mathrm{H}-\mathrm{H}$ & L-H & L-L & H-L \\
\hline 2010 & $\begin{array}{l}\text { Beijing, Tianjin, Hebei, Jilin, } \\
\text { Shanghai, Jiangsu, Zhejiang, } \\
\text { Fujian, Shandong, Hunan, } \\
\text { Guangdong and Hainan }\end{array}$ & $\begin{array}{l}\text { Liaoning, Inner } \\
\text { Mongolia, Henan, } \\
\text { Guangxi and } \\
\text { Chongqing }\end{array}$ & $\begin{array}{l}\text { Hubei, Sichuan, } \\
\text { Yunnan, Shaanxi, } \\
\text { Gansu, Qinghai, } \\
\text { Ningxia and Xinjiang }\end{array}$ & $\begin{array}{l}\text { Shanxi, } \\
\text { Heilongjiang, } \\
\text { Anhui, Jiangxi } \\
\text { and Guizhou }\end{array}$ \\
\hline 2014 & $\begin{array}{l}\text { Beijing, Tianjin, Hebei, } \\
\text { Shanghai, Jiangsu, Zhejiang, } \\
\text { Anhui, Fujian, Shandong, } \\
\text { Henan, Hubei, Hunan, } \\
\text { Guangdong and Hainan }\end{array}$ & $\begin{array}{l}\text { Inner Mongolia, } \\
\text { Liaoning, Jilin, } \\
\text { Guangxi, Chongqing } \\
\text { and Yunnan }\end{array}$ & $\begin{array}{c}\text { Shanxi, Sichuan, } \\
\text { Shaanxi, Gansu, } \\
\text { Qinghai, Ningxia and } \\
\text { Xinjiang }\end{array}$ & $\begin{array}{c}\text { Heilongjiang, } \\
\text { Jiangxi and } \\
\text { Guizhou }\end{array}$ \\
\hline
\end{tabular}

model is used as the final analysis model. In order to avoid multiple collinearity in the model, and to verify the stability of the impact of regional financial ecological environment on enterprise innovation promotion, the model coefficients and their significant changes were tested by adding control variables step by step. Specific regression results are shown in Table 5.

The coefficient of financial ecological environment in the model is positive, which shows that the current financial ecological environment in China has a positive role in promoting green technological innovation of enterprises. Provinces with good financial ecological environment can promote the efficiency of green technological innovation of local enterprises, and the use of innovative resources of enterprises is more efficient because of their higher resource allocation efficiency and better governance environment. The growth of regional financial eco-environment index is positively correlated with the innovation ability of enterprises, which indicates that regional financial development has an obvious promoting effect on the innovation ability of regional enterprises, and supports the hypothesis of this paper. At the same time, the regression coefficients of GOV, EOC, FD and SYS are significantly positive at the level of 5\%. It shows that the regional financial ecological environment is a complex ecosystem, and the sound development of each element can promote the green technological innovation of enterprises.

As far as the results of control variables are concerned, after adding three control variables one by one, the fitting degree of the model is maintained at about $20 \%$, the fitting effect of the model is relatively stable, and the coefficient of core variables has not changed significantly. The coefficients of FDI, PGDP and REG are also positive. The increase of foreign capital introduction ensures that enterprise investment in green technological innovation continues to increase steadily; the increase of PGDP indicates that the improvement of economic development will promote the development of green technological innovation, and the implementation of environmental regulation policy will enhance enterprises' awareness of environmental protection, thus having a positive impact on green technological innovation. 
Table 5. Model estimation results.

\begin{tabular}{|c|c|c|c|c|c|c|c|c|}
\hline & (1) & (2) & (3) & (4) & (5) & (6) & (7) & (8) \\
\hline \multirow[t]{2}{*}{$\mathrm{FE}$} & $0.1079^{\star *}$ & $0.1277^{\star *}$ & $0.1563^{* *}$ & $0.1510^{\star *}$ & $0.1556^{\star *}$ & $0.1604^{* *}$ & $0.1192^{*}$ & $0.1508^{* *}$ \\
\hline & $(0.0506)$ & $(0.0529)$ & $(0.0621)$ & $(0.0647)$ & $(0.0704)$ & $(0.0709)$ & $(0.0681)$ & $(0.0678)$ \\
\hline \multirow[t]{2}{*}{ ECO } & & $0.0621^{\star *}$ & $0.0652^{* *}$ & 0.0748 & 0.0737 & 0.0717 & $0.0790^{* *}$ & $0.0712^{\star}$ \\
\hline & & $(0.0302)$ & $(0.0304)$ & $(0.0490)$ & $(0.0490)$ & $(0.0493)$ & $(0.0401)$ & $(0.0397)$ \\
\hline \multirow[t]{2}{*}{ GOV } & & & $0.0790^{\star *}$ & $0.2496^{\star * *}$ & $0.2464^{\star * *}$ & $0.2475^{\star * *}$ & $0.2340^{\star * *}$ & $0.2292^{* * *}$ \\
\hline & & & $(0.0312)$ & $(0.0308)$ & $(0.0307)$ & $(0.0307)$ & $(0.0282)$ & $(0.0282)$ \\
\hline \multirow[t]{2}{*}{ FD } & & & & $0.1988^{* * *}$ & $0.1957^{\star * *}$ & $0.1961^{\star * *}$ & $0.1577^{* * *}$ & $0.1666^{* * *}$ \\
\hline & & & & $(0.0444)$ & $(0.0442)$ & $(0.0442)$ & $(0.0403)$ & $(0.0403)$ \\
\hline \multirow[t]{2}{*}{ SYS } & & & & & 0.0662 & 0.0633 & $0.0738^{*}$ & $0.0769^{*}$ \\
\hline & & & & & $(0.0411)$ & $(0.0412)$ & $(0.0397)$ & $(0.0395)$ \\
\hline \multirow[t]{2}{*}{ FDI } & & & & & & 0.1782 & $0.5881^{\star *}$ & $0.4959^{*}$ \\
\hline & & & & & & $(0.2785)$ & $(0.2704)$ & $(0.2734)$ \\
\hline \multirow[t]{2}{*}{ PGDP } & & & & & & & $0.0450^{* * *}$ & $0.0408^{\star * *}$ \\
\hline & & & & & & & $(0.0061)$ & $(0.0064)$ \\
\hline \multirow[t]{2}{*}{ REG } & & & & & & & & $0.0092^{\star}$ \\
\hline & & & & & & & & $(0.0049)$ \\
\hline Regional FE & Yes & Yes & Yes & Yes & Yes & Yes & Yes & Yes \\
\hline Year FE & Yes & Yes & Yes & Yes & Yes & Yes & Yes & Yes \\
\hline \multirow{2}{*}{$\lambda$} & $0.3760^{\star * *}$ & $0.3617^{\star * *}$ & $0.3762^{* * *}$ & $0.3564^{* * *}$ & $0.3490^{* * *}$ & $0.3574^{\star * *}$ & $0.3111^{* * *}$ & $0.3012^{\star * *}$ \\
\hline & $(0.0676)$ & $(0.0687)$ & $(0.0677)$ & $(0.0694)$ & $(0.0702)$ & $(0.0708)$ & $(0.0804)$ & $(0.0810)$ \\
\hline$N$ & 300 & 300 & 300 & 300 & 300 & 300 & 300 & 300 \\
\hline $\mathrm{R}^{2}$ & 0.3372 & 0.2262 & 0.2508 & 0.2413 & 0.2027 & 0.2002 & 0.2288 & 0.1925 \\
\hline
\end{tabular}

\subsection{Robustness Test}

Although the panel spatial error model can well test the impact of regional financial ecological environment on technological innovation, it is also necessary to further test the robustness of the model.

Replace the spatial weight matrix. In order to further verify the robustness of the estimation results of the benchmark model, using the same model and estimation method, the "economic adjacent" matrix is selected as a new spatial matrix for robustness test. Economic distance is measured by the absolute reciprocal of the difference in PGDP between provinces I and J. Setting the "economic adjacency" weight matrix takes into account the competition between government departments and enterprises in different regions in the development of green technology innovation strategy interaction, that is, they will refer to the behavior decision of other regions with similar economic level in this region. As shown in Table 6, the estimation results have not changed significantly. The significant coefficients of the main explanatory variables are consistent with the benchmark model, which shows that the empirical results are robust. 
Table 6. Robustness test results.

\begin{tabular}{|c|c|c|c|c|c|c|c|c|}
\hline & (1) & (2) & (3) & (4) & (5) & (6) & (7) & (8) \\
\hline \multirow[t]{2}{*}{$\mathrm{FE}$} & $0.1046^{* *}$ & $0.1037^{\star *}$ & $0.0956^{*}$ & 0.0733 & $0.0986^{*}$ & $0.0847^{\star}$ & $0.1039^{*}$ & $0.0992^{*}$ \\
\hline & $(0.0513)$ & $(0.0521)$ & $(0.0530)$ & $(0.0659)$ & $(0.0517)$ & $(0.0504)$ & $(0.0624)$ & $(0.0509)$ \\
\hline \multirow[t]{2}{*}{ ECO } & & $0.0911^{\star *}$ & $0.0982^{\star *}$ & $0.0915^{\star *}$ & $0.0880^{*}$ & $0.0866^{* *}$ & $0.0874^{*}$ & $0.0870^{*}$ \\
\hline & & $(0.0456)$ & $(0.0449)$ & $(0.0460)$ & $(0.0460)$ & $(0.0422)$ & $(0.0469)$ & $(0.0432)$ \\
\hline \multirow[t]{2}{*}{ GOV } & & & $0.0498^{*}$ & $0.0576^{*}$ & $0.0545^{*}$ & $0.0564^{*}$ & $0.0547^{\star *}$ & $0.0568^{\star}$ \\
\hline & & & $(0.0295)$ & $(0.0327)$ & $(0.0326)$ & $(0.0307)$ & $(0.0275)$ & $(0.0324)$ \\
\hline \multirow[t]{2}{*}{ FIN } & & & & $0.4016^{* * *}$ & $0.4035^{\star * *}$ & $0.4105^{\star * *}$ & $0.3602^{* * *}$ & $0.3898^{\star * *}$ \\
\hline & & & & $(0.0532)$ & $(0.0534)$ & $(0.0538)$ & $(0.0504)$ & $(0.0529)$ \\
\hline \multirow[t]{2}{*}{ SYS } & & & & & $0.0763^{*}$ & $0.0745^{*}$ & $0.0823^{\star *}$ & $0.0834^{* *}$ \\
\hline & & & & & $(0.0401)$ & $(0.0403)$ & $(0.0396)$ & $(0.0394)$ \\
\hline \multirow[t]{2}{*}{ FDI } & & & & & & $0.6565^{\star *}$ & $0.6746^{* *}$ & $0.6067^{\star *}$ \\
\hline & & & & & & $(0.2807)$ & $(0.2688)$ & $(0.2746)$ \\
\hline \multirow[t]{2}{*}{ PGDP } & & & & & & & $0.0327^{* * *}$ & $0.0216^{* * *}$ \\
\hline & & & & & & & $(0.0053)$ & $(0.0057)$ \\
\hline \multirow[t]{2}{*}{ REG } & & & & & & & & $0.0188^{*}$ \\
\hline & & & & & & & & (0.0109) \\
\hline \multirow{2}{*}{$\begin{array}{c}\text { Regional FE } \\
\text { Year FE }\end{array}$} & Yes & Yes & Yes & Yes & Yes & Yes & Yes & Yes \\
\hline & Yes & Yes & Yes & Yes & Yes & Yes & Yes & Yes \\
\hline \multirow{2}{*}{$\lambda$} & $0.2624^{* * *}$ & $0.2576^{* * *}$ & $0.2681^{* * *}$ & $0.2468^{* * *}$ & $0.2234^{* * *}$ & $0.2388^{\star * *}$ & $0.2299^{* * *}$ & $0.2289^{* * *}$ \\
\hline & $(0.0703)$ & $(0.0743)$ & $(0.0753)$ & $(0.0761)$ & $(0.0763)$ & $(0.0771)$ & $(0.0816)$ & $(0.0832)$ \\
\hline $\mathrm{N}$ & 300 & 300 & 300 & 300 & 300 & 300 & 300 & 300 \\
\hline $\mathrm{R}^{2}$ & 0.2346 & 0.2099 & 0.1763 & 0.1844 & 0.2066 & 0.2019 & 0.1861 & 0.1772 \\
\hline
\end{tabular}

Assume variable returns to scale. The explanatory variables selected above are the efficiency of green technology innovation measured by DEA index method, assuming that the scale reward is constant. This assumption can be relaxed in robustness test, assuming that the scale reward is variable, and then estimating using the spatial panel model as well. Regression results are shown as Table 7, these did not change significantly. The significance of the estimated coefficients of the main explanatory variables was consistent with the benchmark model. It shows that the estimation results of the empirical part of this paper are robust.

\section{Conclusions and Suggestions}

\subsection{Conclusions}

The green technological innovation ability of Chinese enterprises shows significant spatial autocorrelation in spatial distribution, and shows an upward trend. Enterprise innovation shows obvious local cluster differentiation. Enterprise green technology innovations in Jiangsu, Zhejiang, Shanghai, Beijing, Tianjin and Hebei 
Table 7. Robustness test results.

\begin{tabular}{|c|c|c|c|c|c|c|c|c|}
\hline & (1) & (2) & (3) & (4) & (5) & (6) & (7) & (8) \\
\hline \multirow[t]{2}{*}{$\mathrm{FE}$} & $0.1085^{\star *}$ & $0.1083^{\star *}$ & 0.0756 & 0.0733 & $0.1086^{*}$ & $0.1047^{\star}$ & $0.1039^{*}$ & $0.0992^{\star}$ \\
\hline & $(0.0508)$ & $(0.0531)$ & $(0.0630)$ & $(0.0659)$ & $(0.0617)$ & $(0.0624)$ & $(0.0624)$ & $(0.0509)$ \\
\hline \multirow[t]{2}{*}{ ECO } & & $0.0771^{*}$ & 0.0582 & 0.0415 & 0.0280 & 0.0266 & 0.0148 & 0.0170 \\
\hline & & $(0.0416)$ & $(0.0419)$ & $(0.0460)$ & $(0.0460)$ & $(0.0462)$ & $(0.0366)$ & $(0.0362)$ \\
\hline \multirow[t]{2}{*}{ GOV } & & & $0.0855^{* * *}$ & $0.0593^{*}$ & $0.0555^{*}$ & $0.0564^{*}$ & $0.0543^{* *}$ & $0.0598^{* * *}$ \\
\hline & & & $(0.0315)$ & $(0.0307)$ & $(0.0306)$ & $(0.0307)$ & $(0.0275)$ & $(0.0274)$ \\
\hline \multirow[t]{2}{*}{ FIN } & & & & $0.2056^{\star * *}$ & $0.2021^{\star * *}$ & $0.2025^{* * *}$ & $0.1620^{* * *}$ & $0.1698^{* * *}$ \\
\hline & & & & $(0.0440)$ & $(0.0437)$ & $(0.0438)$ & $(0.0390)$ & $(0.0389)$ \\
\hline \multirow[t]{2}{*}{ SYS } & & & & & $0.0756^{*}$ & $0.0727^{*}$ & $0.0815^{* *}$ & $0.0834^{* *}$ \\
\hline & & & & & $(0.0421)$ & $(0.0423)$ & $(0.0396)$ & $(0.0394)$ \\
\hline \multirow[t]{2}{*}{ FDI } & & & & & & $0.6655^{\star *}$ & $0.6777^{* *}$ & $0.6023^{* *}$ \\
\hline & & & & & & $(0.2814)$ & $(0.2689)$ & $(0.2716)$ \\
\hline \multirow[t]{2}{*}{ PGDP } & & & & & & & $0.0423^{* * *}$ & $0.0386^{* * *}$ \\
\hline & & & & & & & $(0.0053)$ & $(0.0057)$ \\
\hline \multirow[t]{2}{*}{ REG } & & & & & & & & 0.0081 \\
\hline & & & & & & & & $(0.0049)$ \\
\hline \multirow{2}{*}{$\begin{array}{c}\text { Regional FE } \\
\text { Year FE }\end{array}$} & Yes & Yes & Yes & Yes & Yes & Yes & Yes & Yes \\
\hline & Yes & Yes & Yes & Yes & Yes & Yes & Yes & Yes \\
\hline \multirow{2}{*}{$\lambda$} & $0.2724^{* * *}$ & $0.2546^{\star * *}$ & $0.2691^{\star * *}$ & $0.2412^{\star * *}$ & $0.2298^{\star * \star}$ & $0.2378^{\star * *}$ & $0.2339^{* * *}$ & $0.2499^{* * *}$ \\
\hline & $(0.0725)$ & $(0.0732)$ & $(0.0723)$ & $(0.0741)$ & $(0.0753)$ & $(0.0761)$ & $(0.0836)$ & $(0.0845)$ \\
\hline $\mathrm{N}$ & 300 & 300 & 300 & 300 & 300 & 300 & 300 & 300 \\
\hline $\mathrm{R}^{2}$ & 0.3326 & 0.2599 & 0.1966 & 0.1543 & 0.2073 & 0.2029 & 0.2161 & 0.2072 \\
\hline
\end{tabular}

show obvious spatial agglomeration effect, which may be related to the level of economic development in these areas and the high level of investment in regional scientific and technological innovation. The Southern Comprehensive Economic Zone, with Guangdong as its core, is gradually forming a cluster, while the central and western regions are divided into regions with low innovation activities. At present, the country is also vigorously developing economic and industrial innovation in the western regions.

The empirical results show that there is a significant positive correlation between the financial ecological environment index and the efficiency of green technology innovation. That is to say, the improvement of financial ecological environment is conducive to the development of green technology innovation ability of enterprises. In addition, the sensitivity of green technology innovation to the four sub-environments of financial ecological environment is ranked as: government governance, financial development, system and integrity culture, and economic basis. Financial ecological environment will significantly affect the capital cost and demand for green technological innovation. The better the re- 
gional financial ecological environment is, the lower the capital cost of green technological innovation will be. On the contrary, areas with poor financial ecological environment will invisibly increase the financing cost of enterprise innovation, and the investment of innovation funds is insufficient. Financial ecological environment is closely related to enterprise innovation income. The better the regional financial ecological environment is, the higher the income of enterprise innovation will be.

\subsection{Suggestions}

Firstly, strengthen the restraint mechanism of government behavior and strengthen government supervision. The improvement of financial ecological environment depends largely on the government's governance. First, restrain the government itself by establishing and perfecting its supervision and management institutions, so as to ensure that they do not interfere excessively in the financial market and affect the relative independence of the financial sector. Second, deepen the reform of government system, improve the efficiency of government administration, and give full play to the government's function of guiding financial resources to promote green technology innovation. Third, strengthen the implementation of environmental policies, such as controlling the amount of tradable emission permits, improving the severity of environmental policies, reducing enterprise pollution emissions, and encouraging enterprises to innovate in green technology.

Secondly, give full play to the financing function of Finance and increase investment in green technology innovation. Broaden financing channels for green technological innovation, and ensure the sustained and stable investment of enterprises in green technological innovation. Establish a special green technology innovation fund to stimulate enthusiasm for green technology innovation.

Thirdly, improve the protection system of green technology intellectual property rights and cultivate social honesty consciousness. Maintain fair competition order in the market, enterprises and consumers jointly strengthen trademark awareness, prevent embezzlement and fraudulent use. Strengthen independent intellectual property rights of enterprises from the perspective of safeguarding green development. What's more, we should encourage the growth of credit intermediary service system represented by credit evaluation industry, improve the integrity archival management of enterprises and individuals, strengthen moral restraint, and promote honest and trustworthy social values.

Last but not least, improve the quality and efficiency of economic growth and establish a mechanism for industrial linkage development. Under the background of deepening supply-side reform, on the one hand, all regions should start from effective supply, eliminate backward production capacity, optimize the allocation of stock resources, accelerate technological innovation of enterprises, promote industrial transformation and upgrading, expand high-quality incremental supply, and develop in a direction conducive to intensification and greening. On the other hand, we should strengthen the sense of cooperation and 
innovation among provinces, cities and regions, share advanced technology and superior resources, and strengthen cooperation.

In short, only through the joint efforts of the government, finance, economy, honesty and credit culture system, can we effectively improve the regional financial ecological environment, give full play to the role of regional financial ecological environment in promoting the efficiency of green technological innovation of enterprises, and ultimately promote the systematic and large-scale independent innovation of enterprises in China.

\section{Funding}

This work was supported by the National Social Science Fund of China [15CJY078].

\section{Conflicts of Interest}

The authors declare no conflicts of interest regarding the publication of this paper.

\section{References}

[1] Wu, H.M. and Jin, T.T. (2017) The Financial Eco-Environment and the Efficiency of Firm Innovation. Finance Forum, 22, 57-67.

[2] Braun, E. and Wield, D. (1994) Regulation as a Means for the Social Control of Technology. Technology Analysis \& Strategic Management, 6, 259-272. https://doi.org/10.1080/09537329408524171

[3] Aguilera-Caracuel, J. and Ortiz-de-Mandojana, N. (2013) Green Innovation and Financial Performance: An Institutional Approach. Organization \& Environment, 26, 365-385. https://doi.org/10.1177/1086026613507931

[4] Xu, Q.R. (1997) Management. Higher Education Press, Beijing.

[5] Jiao, C.Y. (2001) Implementing Green Technology Innovation in Enterprise. Science \& Technology Progress and Policy, 3, 73-74. https://doi.org/10.1007/978-1-4615-1689-7_4

[6] Wan, L.L. and Huang, Z.B. (2004) Green Technology Innovation: An Effective Way to Promote the Sustainable Development of China's Economy. Ecological Economy, 6, 29-31.

[7] Dai, J. and Zhang, J.H. (2013) Discrimination, Ownership Structure and Innovative Output of Financial Ownership: Evidence from Industrial Sector in China. Journal of Financial Research, 5, 86-98.

[8] Wan, M. (2014) Analysis on the Green Technology Innovation Based on the Environment Protection. Economy and Management, 12, 14-16.

[9] Zeng, F.Y. (2014) A Study on Technological Innovation and the Mechanism to Upgrade Our Green International Competitiveness. Journal of Anhui University, 5, 90-94.

[10] Wang, Y.J. and Liu, H.H. (2017) The Pathway to Green Technology Innovation: Based on the Rational Analysis of Green Barriers. Ecological Economy, 11, 88-92.

[11] Jiang, F.X., Wang, Z.J. and Bai, J.H. (2013) The Dual Effect of Environmental Regulations' Impact on Innovation-An Empirical Study Based on Dynamic Panel Data of Jiangsu Manufacturing. China Industrial Economics, 7, 44-55. 
[12] Xu, J.Z. and Wang, M.M. (2018) Research on the Threshold Effect of FDI Inflows on Green Technology Innovation and Its Regional Comparison. Science \& Technology Progress and Policy, 10, 1-8.

[13] Demirguc, A. and Maksimovic, V. (1999) Institutions, Financial Markets, and Firm Debt Maturity. Journal of Financial Economics, 54, 79-88. https://doi.org/10.1016/S0304-405X(99)00039-2

[14] Hanley, A., Liu, W.H. and Vaona, A. (2011) Financial Development and Innovation in China: Evidence from the Provincial Data. General Information.

[15] Li, C., Zhong, C.B., Guo, J.W. and Chen, J.X. (2016) Regional Financial Ecological Environment and Enterprise Innovation Ability: Theoretical and Spatial Measurement Inspection. Economy and Management, 5, 19-27.

[16] Li, Y. and Liu, Y.H. (2007) Financial Ecological Environment Assessment in China (2006-2007). China Finance Press, Beijing.

[17] Liu, Y.H. and Chen, X.S. (2011) Financial Ecological Environment Assessment in China (2009-2010). Social Sciences Academic Press (China), Beijing.

[18] Wang, G.G. and Feng, G.H. (2015) Financial Ecological Environment Assessment in China (2013-2014). Social Sciences Academic Press (China), Beijing.

[19] He, G.H. and Peng, S.J. (2012) Research on the Efficiency of Financing Support for Enterprises Independent Innovation in Hubei Province. Science \& Technology Progress and Policy, 29, 43-46.

[20] Zhai, S.B., Xu, Y.Q., Ma, J.J. and Yu, Y. (2015) Financial Ecological Environment, Bank Correlation and Enterprise Risk: Based on Empirical Data of Listed Companies in China. Finance Research, 5, 74-81.

[21] Boyreau-Debray, G. and Wei, S.J. (2005) Pitfalls of a State Dominated Financial System: The Case of China. National Bureau of Economic Research, Cambridge. https://doi.org/10.3386/w11214

[22] Li, J.S. and Hu, Y. (2017) The Influence of Financial Agglomeration on Technological Innovation: Provincial Evidences in China. Finance Forum, 22, 39-52.

[23] Wang, Y., Cheng, L.W. and Wang, H. (2014) Financial Inefficiency, Capital Misallocation and Heterogeneous Firm Two-Stage R\&D. Shanxi University of Finance \& Economics, 36, 46-57.

[24] Wei, Z.H., Wang, Z.J. and Wu, Y.H. (2012) Financial Ecological Environment, Audit Opinion and the Cost of Debt Financing. Auditing Research, 3, 98-105.

[25] Sun, X.H., Wang, Y. and Xu, R. (2015) Financial Development, Financing Restriction Ease and Firm R\&D Investments. Science Research Management, 36, 47-54.

[26] Chowdturya, R.H. and Maung, M. (2012) Financial Market Development and the Effectiveness of R\&D Investment: Evidence from Developed and Emerging Countries. Research in International Business and Finance, 26, 258-272. https://doi.org/10.1016/j.ribaf.2011.12.003

[27] Wei, Y. (2007) Corporate Social Capital and Technological Innovation: An Empirical Research Based on Perspective of Absorptive Capacity. China Industrial Economics, 9, 119-127.

[28] Pan, Y., Dai, Y.Y., Wu, C.P. and Liu, J.L. (2009) Social Capital, Political Connections and Corporate Investment Decision. Economic Research Journal, 44, 82-94.

[29] Zhai, S.B., Li, H.T. and Xu, Y.Q. (2015) Corporate Culture and Business Credit: Does "Integrity" Work? Contemporary Finance \& Economics, 6, 118-129.

[30] Jaffee, D.M. and Russell, T. (1984) Imperfect Information, Uncertainty, and Credit 
Rationing: A Reply. Quarterly Journal of Economics, 99, 869-872. https://doi.org/10.2307/1883130

[31] Magat, W.A. (1978) Pollution Control and Technological Advance: A Dynamics Model of the Firm. Journal of Environmental Economics and Management, 5, 1-25. https://doi.org/10.1016/0095-0696(78)90002-5

[32] Wang, Z.P., Tao, C.Q. and Shen, P.Y. (2014) Regional Green Technical Efficiency with Its Influencing Factors Analysis Based on Ecological Footprint. Population Resources and Environment in China, 24, 35-40.

[33] Luo, Y.X. (2016) Research on the Heterogeneity of Debt Governance Effects, Debt Reconstruction under the Background of Financial Eco-Environment: Empirical Evidence from the Chinese Listed Companies. Accounting Research, 3, 43-49+95. 